Article

\title{
An Empirical Research on Bank Client Credit Assessments
}

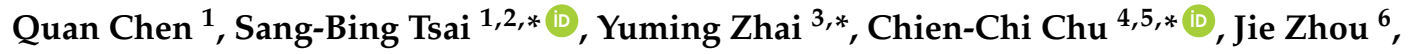 \\ Guodong Li ${ }^{2}$, Yuxiang Zheng ${ }^{7}$, Jiangtao Wang ${ }^{1}$, Li-Chung Chang ${ }^{1}$ and Chao-Feng Hsu ${ }^{1}$
}

1 Zhongshan Institute, University of Electronic Science and Technology of China, Zhongshan 528400, China; zschenquan@gmail.com (Q.C.); jiangtao-w@foxmail.com (J.W.); m13686147477@163.com(L.-C.C.); visonhsu8989@126.com (C.-F.H.)

2 Economics and Management College, Civil Aviation University of China, Tianjin 300300, China, gdli@cauc.edu.cn

3 School of Economics and Management, Shanghai Institute of Technology, Shanghai 201418, China

4 Department of Finance, Business School, Shantou University, Shantou 515063, China

5 Research Institute for Guangdong-Taiwan Business Cooperation, Shantou University, Shantou 515063, China

6 College of Tourism and Service Management, Nankai University, Tianjin 300071, China;

zhoujie_1980@126.com

7 School of Economics \& Management, Shanghai Maritime University, Shanghai 201306, China; yxzheng@shmtu.edu.cn

* Correspondence: jqzhu@stu.edu.cn (C.-C.C.); yumingzhai@126.com (Y.Z.); sangbing@hotmail.com (S.-B.T.)

Received: 25 January 2018; Accepted: 20 April 2018; Published: 3 May 2018

\begin{abstract}
Individual microcredit loans involve large quantities and small amounts and necessitate rapid approval, therefore making simple and fast application approvals rather critical. Creditors must evaluate clients' credit status and default risk within the shortest time when determining whether to approve or decline their applications, preventing overdue responses that negatively impact bank profits and management practices, and could trigger domestic financial crises. This study investigates client credit quality criteria, focusing on the expert opinions of bank managers. The decision-making trial and evaluation laboratory method is adopted to enable a comparison and analysis of the similarities and differences in how banks evaluate their clients' character, ability, financial capability, and collateral. Based on causality and correlations among the criteria, we also identify the core problems and key improvement criteria in the evaluation system. Through survey results of professional managers from Taiwanese banks, this study uses the DEMATEL method to compare the differences in bank evaluation methods based on the four dimensions of clients' character, ability, pockets, and collateral, as well as the corresponding 14 criteria. In order to improve the reliability and usefulness in bank client credit risk assessment, the assessment dimensions and indicators of bank client credit risk assessment are first discussed; second, the causal relationship and degree of mutual influence between different dimensions and criteria are researched and assessed; in the end, the paper discusses how to improve the function and the benefits of bank client credit risk assessment.
\end{abstract}

Keywords: credit assessment; decision making; bank client; finance; sustainability

\section{Introduction}

Banks grant their clients capital loans through which income is generated in the form of the interest paid on that loan, but the quality of credit varies. This is associated with credit collection and is related to the success of bank managers. The principal amount loaned to clients involves with major bank finances and maximum credit exposures. When seeking to improve business performance while fulfilling corporate social responsibility initiatives, credit services are not only a bank's major services 
and assets, but they are also major sources of revenue for the bank. Careful evaluation and selection of quality clients substantially reduce the potential for credit loss, thereby ensuring high returns and profits that benefit the shareholders and their general customers. Credit evaluations typically yield varying results or credit conditions that are based on character, ability, financial capability (i.e., "pockets"), and collateral. The motivation of this study is to provide an objective method for evaluating clients and preventing loss or subjective evaluations that substantially increase the credit risk to banks [1,2].

In terms of the characteristics of consumption microcredit loans, debtors have no need to provide collateral or third-party guarantee, and they only rely on their own credit to gain the loans. As the borrower's credit rating is used as the repayment guarantee, the borrower's repayment ability and individual credit status appear especially important and the costs are also lower when compared with the bank's operation [3,4]. Microcredit loans belong to the group of unsecured credit loans and bank risk from them is larger, but in the consumer finance sector, consumption microcredit loan products are collateral-free and achieve rapid loan approval, and the bank's profit from them is higher. Therefore, Taiwan's many financial institutions are striving to develop client consumption finance business. At present, in Taiwan the auditing system for consumer credit risk of microcredit loans is not perfect and the operations of auditing systems are not mature and sound. Under such a decision-making process, once the organizers are faced with large and urgent credit loan applications, the credit auditing process can further affect credit granting quality, because auditors have heavy workloads and are short-handed, or new employees lack experience. Thus, a bank's credit default risk and losses from bad debts rise, causing the bank's subsequent collection cost to increase and to further affect its operating performance.

Taiwan's bank client credit loans are classified into term loans and cyclic use. (1) Term loans: when the loans are made, the money can be either all appropriated at one time or appropriated in batches, but the amortization amount for each term adopts the method where the principal and interest are amortized on an average basis. In the initial stage, the principal is amortized in small amounts and the interest is amortized in large amounts. Later, the amortization amount of the principal increases gradually and the amortization amount of interest decreases. When the interest rate and amortization terms remain unchanged, the repayment amount per month is fixed to facilitate the clients to withhold and use the capital; (2) Cyclic use: banks appropriate the loans that are approved to clients' current account or give a certain level of loan limit in a manner of overdraft, so that clients can use the capital and repay the loans at any time. In each term, the interest is only paid for the average balance in the month when the capital is used. Some banks provide the minimum payment. The minimum payment refers to a certain ratio that is based on the fixed amount or average to be used, and when the repayment amount exceeds the minimum payment, it is the repayment of the principal. The interest rate is classified into fixed interest rate and floating interest rate according to the adjustment of the interest rate. In terms of current common products on the market, the appropriation and repayment method is amortization at a fixed amount; the pricing method for the interest rate is based on the adjustment of the index rate of fixed deposit and adopts the floating interest rate to calculate the interest $[5,6]$.

This research discusses the evaluation and selection factors for client credit granting quality and adopts Decision Making Trial and Evaluation Laboratory (DEMATEL) to compare and analyze the similarities and the differences in a bank's evaluation for client traits, abilities, financial resources, collaterals, and other dimensions (criteria), according to bank managers' expert opinions. The goal is to find the core problems and key factors to be improved in the evaluation system in terms of the causal relationship and degree of association between evaluation dimensions. 


\section{Literatue Review}

\subsection{Credit Evaluation of Banks on Clients}

Srinivasan and Kim [7] indicated that credit evaluations can be based on theoretical science, which is analyzed using objective methods and applied in credit evaluation models through the experience accumulated by credit decision-making executives and senior credit officers in order to facilitate credit classification or rating and weighting decisions. Because maintaining social credit relationships is expensive, bank loan decisions typically involve adopting a credit scoring model to quantify the credit conditions of loan applicants to determine whether lenders can fulfill their contracts. To establish an effective credit evaluation model, most banks rely on the insights of credit officers. Previous research on credit evaluation primarily use single precise numbers to express the judgment of credit officers, but using such numbers cannot easily express the opinions of credit officers and they tend to undermine the unique opinions that are expressed among some officers. Therefore, this method is inapplicable to actual decision-making environments; the established credit evaluation model does not fulfill the anticatastrophic and sensitivity requirements of a satisfactory evaluation system.

Shipra and Yash [8] adopted the Stepwise Logistic Regression (LR) model to find the factors that are affecting credit risk. The research results show that age, having a telephone or not, living and working time, region, occupation, public sectors or private sectors, monthly income, ownership of dwellings, the number of previous loans, mortgage terms, and other variables have significant effects. Swami [9] researched credit cardholders' behavior to choose bankruptcy. According to the research results, it is reasonable behavior for cardholders to choose bankruptcy when the interest rate is higher; cardholders will decide to go bankrupt alternatively in the season after the debt ratio has increased. It is estimated that the degree that the rate of bad credit card debt exceeding the bankruptcy rate will grow. The interest rate also has a significant effect on cardholders' default.

Swami [9] chose the unemployment rate, money supply (M1A), average per-capita private consumption, and consumption loan rate as the independent variables to analyze consumer behavior to use revolving credit. Diamond [10] analyzed credit cardholders' behavior to use revolving credit and used two measurement methods to discuss credit risk management. In their research, the impact from changes in total environment such as improvement in the unemployment rate and a reduction of income level on consumers is often mentioned. Consumers' sudden unemployement and pay cut will significantly increase the default rate faced by banks. Agarwal and Fama [11] used the unemployment rate to represent the total environment factor, and the results showed that unemployment has a significant effect on credit cardholders' default. Thi [12] indicated that bank loan decisions are determined based on the amount of income or collateral provided by loan applicants and (to a certain degree) the results of qualitative analyses (i.e., the applicants' character, reputation, and social status).

It can be understood from the above-mentioned discussion that previous research on measuring client credit assessment has a very big deficiency. In most research, it is assumed that the assessment criteria are independent of each other and have no mutual influence relationship and causal relationship. Such an assumption actually limits the further development of research on client credit assessment. The DEMATEL Model can transform a complex system into a causal relationship that has a clear structure. In this way, the relationship between the criteria in the complex system is simplified into two groups: cause and effect; and, the degree of mutual influence between criteria is quantified to help to find the core problems and the direction to be improved in the complex system.

\subsection{Criteria of Clients}

This study summarizes four assessment criteria from information regarding the relationships between banks and clients, credit evaluations, repayment ability, and financial conditions on client credit rating methods [9-12]. 


\subsubsection{Character}

Character refers to debtors' willingness to repay an outstanding loan, whereas corporate character refers to enterprises' and managers' behavior and style in management activities and provides an indication of the nature of a corporate's image. Corporate character is similar to personal integrity and it determines the merits of corporate credit. Enterprises and managers that endeavor to repay their debt, regardless of their hardships maintain a satisfactory reputation and are thereby considered to demonstrate excellent character, rendering them qualified for positive credit ratings.

\subsubsection{Ability}

Ability refers to debtors' ability to repay a loan, and it is a crucial credit criterion second to character. Debt-paying ability can include earning power (i.e., the ability to sell goods and generate profits), financing ability (i.e., the ability to efficiently manage finances), and corporate operating conditions.

\subsubsection{Pockets}

Pockets refer to debtors' net assets specifically related to corporate net capital. They determine an enterprise's scale of operations and resilience against risk. From the perspective of debt fulfillment, this primarily refers to the profitability and the realizable value of financial property.

\subsubsection{Collateral}

Collateral has reinforcing effects in strengthening the credit status of clients. Collateral can reduce the level of risk that a bank exposes itself to, although it cannot be used to improve the credit status of a corporation. Therefore, collateral is not considered as a requirement in decisions that are related to issuing credit.

\section{Research Method}

The DEMATEL method analyzes the complex relationship and relevance between the criteria of complex management problems to effectively use the result to simplify the complexity of the problems. This method was developed by Battelle of Geneva Research Center in commemoration of the association $[13,14]$, hoping to solve the conflicts brought by human and technology. At that time, it was mostly applied to researching the problem structure of the world and cooperating with the complex structure to conduct analysis to further develop and adapt to changes. In retrospect of the three related existing fields of research, mode, and data, they were used to research the world's complex and intractable problem at that time, such as race, hunger, environmental protection, energy, and other problems $[15,16]$.

The application of DEMATEL can effectively understand and analyze the complex causal relationship of the problems in various departments of enterprises, so as to observe the degree of mutual influence between factors and clearly quantify and analyze the complex relationship behind the problems. The matrix and relevant mathematical theory are used to calculate the causal relationship and influence degree between all of the elements, so that we can have a systematic and effective understanding of the complex causal relationship between elements, choose a feasible solution and programs to plan to solve the major and minor problems, and find the dynamic behavior in which the causal relationship helps make the decision $[17,18]$.

DEMATEL in recent years has been widely applied to solve problems in various fields. For instance, Tamura, Okanishi, and Akazawa [19] applied DEMATEL mixed with the importance to discuss customers' insecurity factor and improvement for food. Lee et al. [20] integrated QFD, TRIZ, and DEMATEL methods to solve the design conflict problem during the process of developing an innovative product. Lin and $\mathrm{Wu}$ [21] applied Fuzzy DEMA-TEL to discuss group decision problems. Peng et al. [22] applied Kano and DEMATEL to analyze the causal relationship and the degree of 
mutual influence to find the core problems to win orders and took Taiwan's industrial computer industry as the case study. Lee and Hsieh [23] applied DEMATEL to analyze the causal relationship between the service attributes of the telecommunications industry so as to adjust the importance of the service attributes and to solve the competitive ability problem. Tsai et al. [24] used DEMATEL to discuss how manufacturing enterprises win orders and put forward a suitable competitive strategy.

\subsection{The Decision Making Trial and Evaluation Laboratory Analytical Procedure and Process}

According to DEMATEL, analysis can be organized into the following six analytical procedures [25-30].

\subsubsection{Problem Comprehension and Criterion Definition}

To interpretate a problem, complex system components are listed, defined, and acquired through in-depth interviews, literature analysis and investigation, brainstorming, or seeking the opinions of experts.

\subsubsection{Establishing Measurement Scales for the Relations of the Decision Criteria}

Based on the relationships among the criteria, scales measuring the degrees of influence are designed to explain pair-wise comparisons. Specifically, pairs of criteria are compared to evaluate each interviewee's perception on the degree of influence that was exerted by each criterion. Additionally, these evaluations are measured using a 5-point scale ranging from 0 to $4(0=$ no influence, $1=$ low degree of influence, $2=$ moderate degree of influence, $3=$ high degree of influence, and $4=$ extremely high degree of influence).

\subsubsection{Establishing the Direct-Relation Matrix}

Through a survey of expert opinions and a pair-wise comparison of individual criteria according to their degrees of influence, an $n \times n$ direct-relation matrix $X$ with $n$ criteria is constructed. In $X, x_{i j}$ represents the degree of influence of criterion $i$ on criterion $j$, whereas the diagonal criteria $x_{i i}$ in $X$ are set to 0 .

The direct-relation matrix $X$ is:

$$
X=\left[\begin{array}{cccc}
0 & x_{12} & \cdots & x_{1 n} \\
x_{21} & 0 & \cdots & x_{2 n} \\
\vdots & \vdots & \ddots & \vdots \\
x_{n 1} & x_{n 2} & \cdots & 0
\end{array}\right]
$$

Additionally, a semiotic square $S$ is established to represent the positive influences (expressed as "+") and negative influences (expressed as "-").

3.1.4. Calculating the Normalized Direct-Relation Matrix

$$
\lambda=\frac{1}{\operatorname{Max}_{1 \leq i \leq n}\left(\sum_{j=1}^{n} x_{i j}\right)} \text { or } \lambda=\operatorname{Min}\left[\frac{1}{\operatorname{Max}_{1 \leq i \leq n}\left(\sum_{j=1}^{n} x_{i j}\right)}, \frac{1}{\operatorname{Max}_{1 \leq j \leq n}\left(\sum_{i=1}^{n} x_{i j}\right)}\right]
$$

Through the use of (2) and (3), the normalized direct-relation matrix $N$ can be obtained by multiplying the direct-relation matrix $X$ by $\lambda$.

$$
N=\lambda X
$$


According to the assumptions of the DEMATEL method, the sum of at least one row of $i$ must fulfill (4).

$$
\sum_{j=1}^{n} x_{i j}<\frac{1}{\lambda}
$$

Therefore, the normalized direct-relation matrix $N$ is used to obtain the approximate substochastic matrix.

$$
\lim _{K \rightarrow \infty} N^{K}=O \text { and } \lim _{K \rightarrow \infty}\left(I+N+N^{2}+\cdots+N^{K}\right)=(I-N)^{-1}
$$

In (5), $O$ and $I$ denote null and identity matrices, respectively.

\subsubsection{Calculating the Direct-Indirect Relation Matrix}

The direct-relation matrix $N$ exhibits properties specified in (5). Therefore, the direct-indirect relation matrix $T$ or the total-relation matrix can be obtained using (6). Additionally, the indirect relation matrix $H$ or the total indirect relation matrix can be obtained using (7).

$$
\begin{aligned}
& T=\lim _{K \rightarrow \infty}\left(N+N^{2}+\cdots+N^{K}\right)=N(I-N)^{-1} \\
& H=\lim _{K \rightarrow \infty}\left(N+N^{2}+\cdots N^{K}\right)=N^{2}(I-N)^{-1}
\end{aligned}
$$

where $t_{i j}$ represents the criteria in the direct-indirect relation matrix $T$, in which $i, j=1,2, \ldots, n$. Through (8) and (9), the sum of the rows and columns in the direct-indirect relation matrix $T$ can be calculated; $D_{i}$ represents the sum of the $i$ th row, which means the sum of criterion $i$ as the cause influencing other criteria; and, $R_{j}$ represents the sum of the $j$ th column, meaning the sum of criterion $i$ as the effect that is influenced by other criteria. The values of $D_{i}$ and $R_{j}$ obtained from the direct-indirect relation matrix $T$ comprise both direct and indirect influences.

$$
\begin{aligned}
& D_{i}=\sum_{j=1}^{n} t_{i j}(i=1,2, \cdots . n) \\
& R_{i}=\sum_{i=1}^{n} t_{i j}(j=1,2, \cdots . n)
\end{aligned}
$$

\subsubsection{Plotting the Causal Diagram}

In the causal diagram, $\left(D_{k}+R_{k}, D_{k}-R_{k}\right)$ is used to separately represent the horizontal and vertical axes. The average is used as the dividing line along the horizontal axis $\left(D_{k}+R_{k}\right)$, whereas 0.0 is used as the dividing line along the vertical axis $\left(D_{k}-R_{k}\right)$, thereby dividing the causal diagram into four quadrants. Along the horizontal axis, $\left(D_{k}+R_{k}\right)$ is defined as prominence (i.e., $k=i=j=1,2, \ldots$, $n)$, representing the total degree of influence of and the degree of being influenced by this complex system component. This value indicates the degree of prominence of the complex system component $\mathrm{k}$ in all of the problems. The vertical axis $\left(D_{k}-R_{k}\right)$ is defined as the relation, which represents the degree of variation in the influence of and the degree of being influenced by the complex system criteria. This value reflects the degree of causality of criterion $\mathrm{k}$ in all problems; positive and negative signs, respectively, indicate that the component is a cause or an effect. Figure 1 decribes the meaning and characteristics of the four quadrants in the causal diagram. Thus, the complex causal relationships among the criteria can be simplified as a comprehensible structure for interpreting the effects of each criterion on the other criteria. This can be used to provide guidance when seeking new solutions to problems or when reexamining old ones. 


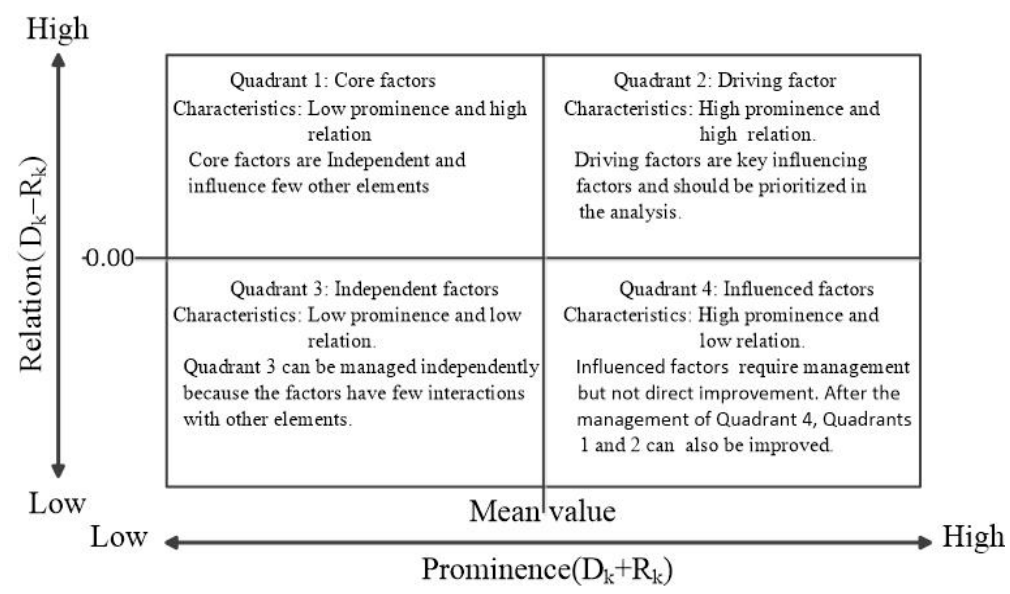

Figure 1. Meanings and Characteristics of the Four Quadrants in the Causal Diagram.

\subsection{Research Design}

Based on the credit rating methods and principles of domestic banks regarding how they evaluate their clients, this study establishes an evaluation framework comprising four dimensions and 14 criteria. Table 1 shows the measurement attributes.

Table 1. Definitions of the evaluation dimensions and criteria.

\begin{tabular}{|c|c|c|}
\hline Dimensions & Criteria & Definition \\
\hline \multirow{4}{*}{ A. Character } & A1. Check credit record & \multirow{4}{*}{$\begin{array}{l}\text { No dishonored check records } \\
\text { Positive evaluation in media or local public opinions } \\
\text { Upright conduct } \\
\text { Free of default records from borrowing or lending from or to } \\
\text { institutions or individuals }\end{array}$} \\
\hline & A2. Social reputation & \\
\hline & A3. Behavior & \\
\hline & A4. Repayment & \\
\hline \multirow{4}{*}{ B. Ability } & B1. Repayment ability & Strong repayment ability and sincerity to fulfill contract \\
\hline & B2. Entrepreneurial ability & Professional skills in research and development and innovation \\
\hline & B3. Finciancing ability & Financing and investment management experience \\
\hline & B4. Profitability & Satisfactory cost and revenue analytic system \\
\hline \multirow{3}{*}{ C. Pocket } & C1. Financial conditions & Fixed normal income, continuously greater than debt \\
\hline & C2. Bank deposit & Bank deposits remain a high-priority aggregate \\
\hline & C3. Securities & Owns listed or over-the-counter stocks or jewelry or hold bars \\
\hline \multirow{3}{*}{ D. Collateral } & D1. Property asset & \multirow{3}{*}{$\begin{array}{l}\text { Owns property assets before pledge or superficies } \\
\text { Owns securities, plants, or equipment before pledge of moveable } \\
\text { Owns multiple intangible assets such as patents, trademarks, } \\
\text { or copyrights }\end{array}$} \\
\hline & D2. Movable Property & \\
\hline & D3. Intangible assets & \\
\hline
\end{tabular}

\section{Results and Discussion}

\subsection{Assessment Criteria Importance Questionnaire Analysis}

This study surveys domestic bank managers using DEMATEL expert questionnaires that are based on the four dimensions and 14 criteria banks use to evaluate the credit status of their clients. The results are described, as follows.

\section{Recovery of Taiwanese Banks' Expert Questionnaire}

The questionnaires were distributed from 5 December 2017 to 26 December 2017. The questionnaire survey adopted a six-point scale as its scoring method: " 5 " represents the biggest influence, " 0 " represents no influence, and the middle scores are given according to the degree of importance. 
The banks participating in this study are one state-run bank (288 branches; $9.1 \%$ market share on loans), one private bank (164 branches; $4.7 \%$ market share on loans), and one foreign subsidiary bank in Taiwan (64 branches; $1.1 \%$ market share on loans). Among the participants, there are 21 credit executives with more than 20 years of service. Among the 25 valid questionnaires, $14(77.78 \%)$ of the participating credit executives are high-level managers (e.g., directors, regional service center managers, branch managers), and 11 (22.22\%) are intermediate-level managers (e.g., regional service center assistant managers, branch assistant managers, assistant directors), as shown in Table 2.

Table 2. Domestic bank expert questionnaire return rates.

\begin{tabular}{lcc}
\hline \multicolumn{1}{c}{ Position } & Number of Questionnaires & Return Rate \\
\hline $\begin{array}{l}\text { 1. High-level managers (i.e., directors, regional center managers, } \\
\text { branch managers) }\end{array}$ & 14 & $77.78 \%$ \\
\hline $\begin{array}{l}\text { 2. Intermediate-level managers (regional center assistant managers, } \\
\text { branch assistant managers, assistant directors) }\end{array}$ & 11 & $22.22 \%$ \\
\hline Total & 25 & $100 \%$ \\
\hline
\end{tabular}

\subsection{Assessment Dimensions and Criteria Analysis}

\subsubsection{Dimension Analysis}

Table 3 shows the survey result of 25 expert opinions, and their scores are averaged where the number is correct to the second decimal place to gain the survey table for the four dimensions.

Table 3. Direct-relation matrix $X$.

\begin{tabular}{ccccc}
\hline Dimension & Character (A) & Ability (B) & Pockets (C) & Collateral (D) \\
\hline Character (A) & 0.00 & 2.88 & 1.00 & 0.00 \\
Ability (B) & 2.56 & 0.00 & 2.00 & 1.00 \\
Pockets (C) & 2.00 & 2.52 & 0.00 & 0.00 \\
Collateral (D) & 2.00 & 2.44 & 3.00 & 0.00 \\
\hline
\end{tabular}

The calculation of normalized direct-relation matrix is based on the column vector and the maximum and the reciprocal of maximum in the sum of each column are taken as the $\lambda$ value. According to the calculation of Equations (2) and (3), the direct-relation matrix $X$ is multiplied by the $\lambda$ value to gain the normalized direct-relation matrix $N$ and the influence coefficient is acquired by adopting the round method to be correct to the second decimal place. Please refer to Table 4.

Table 4. Normalized direct-relation Matrix N.

\begin{tabular}{ccccc}
\hline Dimension & Character (A) & Ability (B) & Pockets (C) & Collateral (D) \\
\hline Character (A) & 0.00 & 0.39 & 0.13 & 0.00 \\
Ability (B) & 0.34 & 0.00 & 0.27 & 0.13 \\
Pockets (C) & 0.27 & 0.34 & 0.00 & 0.00 \\
Collateral (D) & 0.27 & 0.33 & 0.40 & 0.00 \\
\hline
\end{tabular}

Equations (3) and (4) are then used to calculate the Direct-indirect matrix T. The Direct-indirect criteria matrix is in Table 5. 
Table 5. Direct-indirect relation matrix $T$.

\begin{tabular}{ccccc}
\hline Threshold $=\mathbf{0 . 7 6 1}$ & Character (A) & Ability (B) & Pockets (C) & Collateral (D) \\
\hline Character (A) & 0.379 & 0.705 & 0.413 & 0.095 \\
Ability (B) & 0.761 & 0.570 & 0.609 & 0.211 \\
Pockets (C) & 0.628 & 0.721 & 0.317 & 0.097 \\
Collateral (D) & 0.874 & 0.995 & 0.842 & 0.134 \\
\hline
\end{tabular}

In the end, Equation (5)-(7) are used to calculate the $D i$ values in each column and $R_{j}$ values in each row and gain the Prominence $(D+R)$ and Relation $(D-R)$. The total influence given and received on dimensions and criteria is summarized in Table 6.

Table 6. Summary table of dematel prominence and relation.

\begin{tabular}{ccccc}
\hline Dimension & D & R & D + R & D $-\mathbf{R}$ \\
\hline Character (A) & 1.591 & 2.642 & 4.233 & -1.050 \\
Ability (B) & 2.151 & 2.991 & 5.143 & -0.840 \\
Pockets (C) & 1.764 & 2.182 & 3.946 & -0.418 \\
Collateral (D) & 2.845 & 0.536 & 3.381 & 2.308 \\
\hline
\end{tabular}

According to the result in Table 6, how Taiwan's bank managers look at the causal relationship and degree of mutual influence between the four dimensions of client credit assessment are described below.

(1) High Relation and Higher Prominence: mainly including the dimension of Collateral (D). This dimension is the core item influencing other dimensions and represents the driving factor of problem solving.

(2) Low Relation and High Prominence: including two dimensions of Character (A) and Ability (B). The two dimensions are the items belonging to the result category and are influenced by other dimensions.

(3) Low Relation and Low Prominence: the dimension of Pockets (C) is influenced by other dimensions, but the influence degree is small, representing that this dimension has relative independence.

According to the research results, among the 4 dimensions of the client credit assessment, the dimension of Collateral (D) is the core item influencing other dimensions; the two dimensions of Character (A) and Ability (B) are the items belonging to the result category and are influenced by other dimensions; the dimension of Pockets $(C)$ is influenced by other dimensions, but the influence degree is small, representing that this dimension has the relative independence.

\subsubsection{Attribute (Criteria) Analysis for the Dimension of Character}

This research analyzed the mutual influence relationship of the attributes in each dimension. Based on the aforesaid Equation (2) to Equation (7), the summary table can also be calculated for the Direct-indirect relation matrix, Prominence, and Relation of all the attributes (criteria) in this dimension. Please refer to Tables 7 and 8.

Table 7. Direct-indirect relation matrix $T$.

\begin{tabular}{ccccc}
\hline Threshold = 4.894 & $\begin{array}{c}\text { Check Credit Record } \\
\text { (A1) }\end{array}$ & $\begin{array}{c}\text { Social Reputation } \\
\text { (A2) }\end{array}$ & $\begin{array}{c}\text { Behavior } \\
\text { (A3) }\end{array}$ & $\begin{array}{c}\text { Repayment Records } \\
\text { (A4) }\end{array}$ \\
\hline Check credit record (A1) & 4.696 & 5.074 & 5.071 & 5.019 \\
Social reputation (A2) & 4.594 & 4.491 & 4.731 & 4.670 \\
Behavior (A3) & 4.765 & 4.894 & 4.646 & 4.822 \\
Repayment records (A4) & 4.728 & 4.840 & 4.848 & 4.551 \\
\hline
\end{tabular}


Table 8. Summary table of prominence and relation in the dimension of character.

\begin{tabular}{ccccc}
\hline Management Ability Criteria & Row Total (D) & Column Total (R) & D + R & D - R \\
\hline Check credit record (A1) & 19.860 & 18.783 & 38.643 & 1.077 \\
Social reputation (A2) & 18.486 & 19.298 & 37.784 & -0.812 \\
Behavior (A3) & 19.127 & 19.297 & 38.424 & -0.170 \\
Repayment records (A4) & 18.967 & 19.062 & 38.029 & -0.095 \\
\hline
\end{tabular}

According to the result in Table 8, how Taiwan's bank managers look at the causal relationship and degree of mutual influence between the four attributes in the dimension of Character are described below.

(1) High Relation and Higher Prominence: mainly including the attribute of Check credit record (A1). This attribute is the core item influencing other attributes and represents the driving factor of problem solving.

(2) Low Relation and High Prominence: mainly including the attribute of Behavior (A3). This attribute is the item belonging to the result category and is influenced by other attributes.

(3) Low Relation and Low Prominence: the two attributes of Repayment records (A4) and Social reputation (A2) are influenced by other attributes, but the influence degree is small, representing that this attribute has relative independence.

According to the research results, in the dimension of Character of client credit assessment, the attribute of Check credit record (A1) is the core item influencing other attributes; the attribute of Behavior (A3) is the item that is belonging to the result category and is influenced by other attributes; the two attributes of Repayment records (A4) and Social reputation (A2) are influenced by other attributes, but the influence degree is small, representing that this attribute has relative independence.

\subsubsection{Attribute (Criteria) Analysis for the Dimension of Ability}

Based on the aforesaid Equation (2) to Equation (7), the summary table can also be calculated for the Direct-indirect relation matrix, Prominence, and Relation of all the attributes (Criteria) in this dimension. Please refer to Tables 9 and 10.

According to the result in Table 10, how Taiwan's bank managers look at the causal relationship and the degree of mutual influence between the four attributes in the dimension of Ability are described below.

(1) High Relation and Higher Prominence: mainly including the two attributes of Financing ability (B3) and Profitability (B4). The two attributes are the core items influencing other dimensions and represent the driving factor of problem solving.

(2) Low Relation and High Prominence: mainly including the two attributes of Repayment ability (B1) and Entrepreneural ability (B2). The two attributes are the items belonging to result category and are influenced by other attributes.

According to the research results, in the dimension of Ability of client credit assessment, the two attributes of Financing ability (B3) and Profitability (B4) are the core items influencing other attributes and represent the driving factor of problem solving. The two attributes of Repayment ability (B1) and Entrepreneural ability (B2) are influenced by other attributes, but the influence degree is small, representing that this kind of attribute has relative independence. 
Table 9. Direct-indirect relation matrix $T$.

\begin{tabular}{ccccc}
\hline Threshold $=\mathbf{2 0 . 3 1 2}$ & $\begin{array}{c}\text { Repayment Ability } \\
\text { (B1) }\end{array}$ & $\begin{array}{c}\text { Entrepreneural Ability } \\
\text { (B2) }\end{array}$ & $\begin{array}{c}\text { Financing Ability } \\
\text { (B3) }\end{array}$ & $\begin{array}{c}\text { Profitability } \\
\text { (B4) }\end{array}$ \\
\hline Repayment ability (B1) & 19.746 & 19.952 & 18.638 & 18.026 \\
Entrepreneural ability (B2) & 20.444 & 20.126 & 19.040 & 18.441 \\
Financing ability (B3) & 20.508 & 20.451 & 18.860 & 18.496 \\
Profitability (B4) & 20.312 & 20.253 & 18.909 & 18.083 \\
\hline
\end{tabular}

Table 10. Summary table of prominence and relation in the dimension of ability.

\begin{tabular}{ccccc}
\hline Repayment Ability Criteria & Row Total (D) & Column Total (R) & D + R & D - R \\
\hline Repayment ability (B1) & 76.363 & 81.010 & 157.373 & -4.647 \\
Entrepreneural ability (B2) & 78.050 & 80.782 & 158.832 & -2.732 \\
Financing ability (B3) & 78.315 & 75.447 & 153.762 & 2.868 \\
Profitability (B4) & 77.558 & 73.046 & 150.604 & 4.512 \\
\hline
\end{tabular}

\subsubsection{Attribute (Criteria) Analysis for the Dimension of Pockets}

Based on the aforesaid Equation (2) to Equation (7), the summary table can also be calculated for the Direct-indirect relation matrix, Prominence, and Relation of all the attributes (Criteria) in this dimension. Please refer to Tables 11 and 12.

According to the result in Table 12, how Taiwan's bank managers look at the causal relationship and the degree of mutual influence between the three attributes in the dimension of Pockets are described below.

(1) High Relation and Higher Prominence: mainly including the attribute of Financial conditions (C1). This attribute is the core item influencing other attributes and represents the driving factor of problem solving.

(2) Low Relation and High Prominence: mainly including the attribute of Bank deposit (C2). This attribute is the item belonging to result category and is influenced by other attributes.

(3) Low Relation and Low Prominence: mainly including the attribute of Securities (C3). This attribute is influenced by other attributes, but the influence degree is small, representing that this attribute has relative independence.

According to the research results, in the dimension of Pockets of client credit assessment, the attribute of Financial conditions (C1) is the core item influencing other attributes. The attribute of Bank deposit (C2) is the item belonging to result category and is influenced by other attributes. The attribute of Securities (C3) is influenced by other attributes, but the influence degree is small, representing that this kind of attribute has relative independence.

Table 11. Direct-indirect relation matrix $T$.

\begin{tabular}{cccc}
\hline Threshold $=\mathbf{9 . 7 7 5}$ & Financial Conditions (C1) & Bank Deposit (C2) & Securities (C3) \\
\hline Financial conditions (C1) & 9.891 & 10.274 & 9.969 \\
Bank deposit (C2) & 10.037 & 9.740 & 9.775 \\
Securities (C3) & 9.732 & 9.768 & 9.180 \\
\hline
\end{tabular}

Table 12. Summary table of prominence and relation in the dimension of pockets.

\begin{tabular}{ccccc}
\hline Financing Ability Criteria & Row Total (D) & Column Total (R) & D + R & D - R \\
\hline Financial conditions (C1) & 30.134 & 29.661 & 59.795 & 0.474 \\
Bank deposit (C2) & 29.552 & 29.782 & 59.335 & -0.230 \\
Securities (C3) & 28.681 & 28.924 & 57.605 & -0.243 \\
\hline
\end{tabular}




\subsubsection{Attribute (Criteria) Analysis for the Dimension of Collateral}

Based on the aforesaid Equation (2) to Equation (7), the summary table can also be calculated for the Direct-indirect relation matrix, Prominence, and Relation of all the attributes (criteria) in this dimension. Please refer to Tables 13 and 14.

According to the result in Table 14, how Taiwan's bank managers look at the causal relationship and degree of mutual influence between the three attributes in the dimension of Collateral (D) are described below.

(1) High Relation and Higher Prominence: mainly including the attribute of Property asset (D1). This attribute is the core item influencing other attributes and represents the driving factor of problem solving.

(2) Low Relation and High Prominence: mainly including the two attributes of Movable property (D2) and Intangible assets (D3). The two attributes are the items belonging to result category and are influenced by other attributes.

According to the research results, in the dimension of Collateral (D) of client credit assessment, the attribute of Property asset (D1) is the core item influencing other attributes. The two attributes of Movable property (D2) and Intangible assets (D3) are the items that are belonging to result category and are influenced by other attributes.

Table 13. Direct-indirect relation matrix $T$.

\begin{tabular}{cccc}
\hline Threshold $=\mathbf{4 . 3 3 5}$ & Property Asset (D1) & Movable Property (D2) & Intangible Assets (D3) \\
\hline Property asset (D1) & 3.961 & 4.806 & 4.715 \\
Movable property (D2) & 3.922 & 4.097 & 4.335 \\
Intangible assets (D3) & 4.001 & 4.511 & 4.100 \\
\hline
\end{tabular}

Table 14. Summary table of prominence and relation in the dimension of collateral.

\begin{tabular}{ccccc}
\hline Collateral Criteria & Row Total (D) & Column Total (R) & D + R & D - R \\
\hline Property asset (D1) & 13.483 & 11.884 & 25.367 & 1.598 \\
Movable property (D2) & 12.354 & 13.414 & 25.768 & -1.061 \\
Intangible assets (D3) & 12.613 & 13.151 & 25.764 & -0.537 \\
\hline
\end{tabular}

\subsection{Analysis and Discussion}

According to the research results, among the four dimensions of client credit assessment, the dimension of Collateral (D) is the core item influencing other dimensions, represents the driving factor of problem solving, and is the most important item among the four dimensions and should be given a higher weight. In the dimension of Collateral (D), the attribute of Property asset (D1) is the core item influencing other attributes and is the most important item; the two attributes of Movable property (D2) and Intangible assets (D3) are the items that are belonging to result category and are influenced by other attributes.

The two dimensions of Character (A) and Ability (B) are the items that are belonging to result category and are influenced by other dimensions; the dimension of Pockets (C) is influenced by other dimensions, but the influence degree is small, representing that this dimension has relative independence. If the three dimensions are analyzed continuously, and then the less important assessment attributes are chosen from them. In the dimension of Character (A) of client credit assessment, the attribute of Check credit record (A1) is the core item influencing other attributes. In the dimension of Ability (B) of client credit assessment, the two attributes of Financing ability (B3) and Profitability (B4) are the core items that are influencing other attributes. In the dimension of Pockets (C) of client credit assessment, the attribute of Financial conditions (C1) is the core item influencing other attributes. 


\section{Conclusions}

From the perspective of credit risk management, banks absorb the public's own capital income generated through interest from loans or investments as profits. The credit and market risks that banks assume influence their clients who bank with them as well as their shareholders. Banks' lending behaviors to clients correspond to credit collection risks in which the quality of a client's character and trust relationship are the key factors that are influencing credit risks. Therefore, banks' client quality management impacts the effectiveness of credit risk management.

In terms of the overall financial environment, Taiwan's financial system has undergone several reforms. However, many banks compete with each other by reducing their prices to attract credit clients and to boost their profit and market share. Consequently, quality screening of clients is frequently overlooked, resulting in credit losses. In contrast to managing and controlling credit asset quality, client screening is particularly crucial.

The DEMATEL model can transform the complex system into a causal relationship with a clear structure. In this way, the relationship between the criteria in the complex system is simplified into two groups: cause and effect, and the degree of mutual influence between criteria is quantified to help find the core problems and the direction to be improved in the complex system. Through survey results from professional managers in Taiwanese banks, this study uses DEMATEL to compare the differences in bank evaluation methods that are based on the four dimensions of clients' character, ability, pockets, and collateral, as well as the corresponding 14 criteria.

According to the research results, among the 4 dimensions of client credit assessment, the dimension of Collateral (D) is the core item influencing other dimensions, represents the driving factor of problem solving, and is the most important item among the 4 and should be given a higher weight. In the dimension of Collateral (D), the attribute of Property asset (D1) is the core item influencing other attributes and is the most important item. The two attributes of Movable property (D2) and Intangible assets (D3) are the items belonging to result category and are influenced by other attributes.

This research contributes to the literature and can also be applied to real-world practice in the financial industry. However, it is suggested that future researchers should choose more cases for further discussion. It is also recommended that other researchers should use other assessment methods for analysis and comparison.

Author Contributions: Writing: Q.C., S.-B.T., C.-C.C., J.Z.; Providing case and idea: S.-B.T.; J.W.; L.-C.C., C.-F.H.; Providing revised advice: C.-C.C., Y.Zhai, G.L., Y.Zheng.

Acknowledgments: This research was supported by the National Social Science Foundation of China (Grant Number: 15BGL019), Shanghai Social Science Foundation (Grant Number: 2014BGL004); Zhongshan City Science and Technology Bureau Project (No. 2017B1015); Provincial Nature Science Foundation of Guangdong (Nos. 2015A030310271 and 2015A030313679 and 416N07); UESTC-ZSC No. (415YKQ10, 417NYP01, 416YCQ09, JC201704) and The Institute of Guangdong and Taiwan of Shantou University for their financial support.

Conflicts of Interest: The authors declare no conflict of interest.

\section{Appendix A. Bank Client Credit Assessments-Questionnaire}

1. Instructions

This questionnaire was designed to collect opinions from experts regarding an issue. Your responses will be subjected to an analysis, the results of which will serve as the basis of our research.

\section{Questionnaire content-Dimension}

For each question, a 6-point scale is used to indicate level of influence of each criterion. Please complete each question by answering " $0-5$ " score to indicate the level of influence that each listed dimension has on the other 4 dimension.

(1) Please indicate the level of influence for the other 4 dimension. 


\begin{tabular}{|c|c|c|c|c|}
\hline Dimension & Character & Ability & Pockets & Collateral \\
\hline Character & - & & & \\
\hline
\end{tabular}

(2) Please indicate the level of influence for the other 4 dimension.

\begin{tabular}{|c|c|c|c|c|}
\hline Dimension & Character & Ability & Pockets & Collateral \\
\hline Ability & & - & & \\
\hline
\end{tabular}

(3) Please indicate the level of influence for the other 4 dimension.

\begin{tabular}{|c|c|c|c|c|}
\hline Dimension & Character & Ability & Pockets & Collateral \\
\hline Pockets & & & - & \\
\hline
\end{tabular}

(4) Please indicate the level of influence for the other 4 dimension.

\begin{tabular}{|c|c|c|c|c|}
\hline Dimension & Character & Ability & Pockets & Collateral \\
\hline Collateral & & & & - \\
\hline
\end{tabular}

3. Questionnaire content-Criteria Analysis for the Dimension of Character

For each question, a 6-point scale is used to indicate level of influence of each criterion. Please complete each question by answering " $0-5$ " score to indicate the level of influence that each listed criteria has on the other 4 criteria.

(1) Please indicate the level of influence for the other 4 criteria:

\begin{tabular}{|c|c|c|c|c|}
\hline Criteria & Check credit record & Social reputation & Behavior & Repayment \\
\hline Check credit record & - & & & \\
\hline
\end{tabular}

(2) Please indicate the level of influence for the other 4 criteria:

\begin{tabular}{|c|c|c|c|c|}
\hline Criteria & Check credit record & Social reputation & Behavior & Repayment \\
\hline Social reputation & & - & & \\
\hline
\end{tabular}

(3) Please indicate the level of influence for the other 4 criteria:

\begin{tabular}{|c|c|c|c|c|}
\hline Criteria & Check credit record & Social reputation & Behavior & Repayment \\
\hline Behavior & & & - & \\
\hline
\end{tabular}

(4) Please indicate the level of influence for the other 4 criteria:

\begin{tabular}{|c|c|c|c|c|}
\hline Criteria & Check credit record & Social reputation & Behavior & Repayment \\
\hline Repayment & & & & - \\
\hline
\end{tabular}

4. Questionnaire content-Criteria Analysis for the Dimension of Ability

For each question, a 6-point scale is used to indicate level of influence of each criterion. Please complete each question by answering " $0-5$ " score to indicate the level of influence that each listed criteria has on the other 4 criteria.

(1) Please indicate the level of influence for the other 4 criteria:

\begin{tabular}{|c|c|c|c|c|}
\hline Criteria & Repayment ability & Entrepreneurial ability & Finciancing ability & Profitability \\
\hline Repayment ability & - & & & \\
\hline
\end{tabular}

(2) Please indicate the level of influence for the other 4 criteria: 


\begin{tabular}{|c|c|c|c|c|}
\hline Criteria & Repayment ability & Entrepreneurial ability & Finciancing ability & Profitability \\
\hline Entrepreneurial ability & & - & & \\
\hline
\end{tabular}

(3) Please indicate the level of influence for the other 4 criteria:

\begin{tabular}{|c|c|c|c|c|}
\hline Criteria & Repayment ability & Entrepreneurial ability & Finciancing ability & Profitability \\
\hline Finciancing ability & & & - & \\
\hline
\end{tabular}

(4) Please indicate the level of influence for the other 4 criteria:

\begin{tabular}{|c|c|c|c|c|}
\hline Criteria & Repayment ability & Entrepreneurial ability & Finciancing ability & Profitability \\
\hline Profitability & & & - & \\
\hline
\end{tabular}

5. Questionnaire content-Criteria Analysis for the Dimension of Pocket

For each question, a 6-point scale is used to indicate level of influence of each criterion. Please complete each question by answering " $0-5$ " score to indicate the level of influence that each listed criteria has on the other 3 criteria.

(1) Please indicate the level of influence for the other 3 criteria:

\begin{tabular}{|c|c|c|c|}
\hline Criteria & Financial conditions & Bank deposit & Securities \\
\hline Financial conditions & - & & \\
\hline
\end{tabular}

(2) Please indicate the level of influence for the other 3 criteria:

\begin{tabular}{|c|c|c|c|}
\hline Criteria & Financial conditions & Bank deposit & Securities \\
\hline Bank deposit & & - & \\
\hline
\end{tabular}

(3) Please indicate the level of influence for the other 3 criteria:

\begin{tabular}{|c|c|c|c|}
\hline Criteria & Financial conditions & Bank deposit & Securities \\
\hline Securities & & & - \\
\hline
\end{tabular}

6. Questionnaire content-Criteria Analysis for the Dimension of Collateral

For each question, a 6-point scale is used to indicate level of influence of each criterion. Please complete each question by answering " $0-5$ " score to indicate the level of influence that each listed criteria has on the other 3 criteria.

(1) Please indicate the level of influence for the other 3 criteria:

\begin{tabular}{|c|c|c|c|}
\hline Criteria & Property asset & Movable Property & Intangible assets \\
\hline Property asset & - & & \\
\hline
\end{tabular}

(2) Please indicate the level of influence for the other 3 criteria:

\begin{tabular}{|c|c|c|c|}
\hline Criteria & Property asset & Movable Property & Intangible assets \\
\hline Movable Property & & - & \\
\hline
\end{tabular}

(3) Please indicate the level of influence for the other 3 criteria:

\begin{tabular}{|c|c|c|c|}
\hline Criteria & Property asset & Movable Property & Intangible assets \\
\hline Intangible assets & & - & \\
\hline
\end{tabular}




\section{References}

1. Aebi, V.; Sabato, G.; Schmid, M. Risk management, corporate governance, and bank performance in the financial crisis. J. Bank. Financ. 2012, 36, 3213-3226. [CrossRef]

2. Jiang, G.J.; Lo, I. Private information flow and price discovery in the U.S. treasury market. J. Bank. Financ. 2014, 47, 118-133. [CrossRef]

3. Bah, R.; Dumontier, P. R\&D Intensity and Corporate Financial Policy: Some International Evidence. J. Bus. Financ. Account. 2001, 28, 671-692.

4. Jan, P.K.; Martin, W. Generally accepted rating principles: A primer. J. Bank. Financ. 2001, 25, 3-23.

5. Mora, N. Reason for Reserve? Reserve Requirements and Credit. J. Money Credit Bank. 2014, 46, 469-501. [CrossRef]

6. Boyd, J.H.; Prescott, E.C. Financial Intermediary Coalitions. J. Econ. Theory 1986, 38, 211-232. [CrossRef]

7. Srinivasan, V.; Kim, Y.H. Designing Expert Financial Systems-A Case Study of Corporate Credit Management. Financ. Manag. 1988, 17, 32-44. [CrossRef]

8. Shipra, B.; Yash, P.T. Comparative Study on Performance Evaluation of Large Cap Equity and Debt Mutual Fund Schemes. Open J. Financ. 2014, 3, 1-13.

9. Swami, M.B. The Impact of liberalization of regulation in Banking Sector: Case Study of Botswana Banking Sector. Open J. Financ. 2014, 6, 1-10.

10. Diamond, D.W. Financial Intermediation and Delegated Monitoring. Rev. Econ. Stud. 1984, 51, $393-414$. [CrossRef]

11. Fama, E. What's Different about Banks? J. Monetary Econ. 1985, 15, 29-39. [CrossRef]

12. Dinh, T.H.T.; Kleimeier, S. A credit scoring model for Vietnam's retail banking market. Int. Rev. Financ. Anal. 2007, 16, 471-495. [CrossRef]

13. Tsai, S.-B. Using the DEMATEL model to explore the job satisfaction of research and development professionals in china's photovoltaic cell industry. Renew. Sustain. Energy Rev. 2018, 81, 62-68. [CrossRef]

14. Lee, Y.C.; Hsiao, Y.C.; Peng, C.F.; Tsai, S.B.; Wu, C.H.; Chen, Q. Using Mahalanobis-Taguchi system, logistic regression, and neural network method to evaluate purchasing audit quality. Proc. Inst. Mech. Eng. Part B J. Eng. Manuf. 2014. [CrossRef]

15. Liu, B.; Li, T.; Tsai, S.-B. Low carbon strategy analysis of competing supply chains with different power structures. Sustainability 2017, 9, 835. [CrossRef]

16. Huang, Z.; Nie, J.; Tsai, S.-B. Dynamic Collection Strategy and Coordination of a Remanufacturing Closed-Loop Supply Chain under Uncertainty. Sustainability 2017, 9, 683. [CrossRef]

17. Qu, Q.; Tsai, S.-B.; Tang, M.; Xu, C.; Dong, W. Marine ecological environment management based on ecological compensation mechanisms. Sustainability 2016, 8, 1267. [CrossRef]

18. Tsai, S.-B.; Yu, J.; Ma, L.; Luo, F.; Zhou, J.; Chen, Q.; Xu, L. A study on solving the production process problems of the photovoltaic cell industry. Renew. Sustain. Energy Rev. 2018, 82, 3546-3553. [CrossRef]

19. Tamura, H.; Okanishi, H.; Akazawa, K. Decision support for extracting and dis-solving consumers' uneasiness over foods using stochastic DEMATEL. J. Telecommun. Inf. Technol. 2006, 4, 91-95.

20. Lee, S.-C.; Su, J.M.; Tsai, S.-B.; Lu, T.-L.; Dong, W. A comprehensive survey of government auditors' self-efficacy and professional Development for improving audit quality. SpringerPlus 2016, 5, 1263. [CrossRef] [PubMed]

21. Lin, C.J.; Wu, W.W. A causal analytical method for group decision making under fuzzy environment. Expert Syst. Appl. 2008, 34, 205-213. [CrossRef]

22. Peng, C.-F.; Ho, L.-H.; Tsai, S.-B.; Hsiao, Y.-C.; Zhai, Y.; Chen, Q.; Chang, L.-C.; Shang, Z. Applying the Mahalanobis-Taguchi System to Improve Tablet PC Production Processes. Sustainability 2017, 9, 1557. [CrossRef]

23. Lee, Y.C.; Hsieh, Y.F. Integration of revised simultaneous importance performance analysis and decision making trial and evaluation laboratory-A study of mobile telecommunication industry in Taiwan. Afr. J. Bus. Manag. 2011, 5, 2312-2321.

24. Tsai, S.-B.; Zhou, J.; Gao, Y.; Wang, J.; Li, G.; Zheng, Y.; Ren, P.; Xu, W. Combining FMEA with DEMATEL Models to Solve Production Process Problems. PLoS ONE 2017, 12, e0183634. [CrossRef] [PubMed] 
25. Liu, W.; Wei, Q.; Huang, S.Q.; Tsai, S.B. Doing Good Again? A Multilevel Institutional Perspective on Corporate Environmental Responsibility and Philanthropic Strategy. Int. J. Environ. Res. Public Health 2017, 14, 1283. [CrossRef] [PubMed]

26. Wang, J.; Yang, J.M.; Chen, Q.; Tsai, S.B. Collaborative Production Structure of Knowledge Sharing Behavior in Internet Communities. Mob. Inf. Syst. 2016. [CrossRef]

27. Du, P.; Xu, L.; Chen, Q.; Tsai, S.B. Pricing competition on innovative product between innovator and entrant imitator facing strategic customers. Int. J. Prod. Res. 2016. [CrossRef]

28. Liu, W.; Shi, H.B.; Zhang, Z.; Tsai, S.B.; Zhai, Y.; Chen, Q.; Wang, J. The Development Evaluation of Economic Zones in China. Int. J. Environ. Res. Public Health 2018, 15, 56. [CrossRef] [PubMed]

29. Chin, T.; Tsai, S.B.; Fang, K.; Zhu, W.; Yang, D.; Liu, R.H.; Tsuei, R.T.C. EO-Performance relationships in reverse internationalization by Chinese Global Startup OEMs: Social networks and strategic flexibility. PLOS ONE 2016, 11, e0162175. [CrossRef] [PubMed]

30. Lee, Y.C.; Wang, Y.C.; Chien, C.H.; Wu, C.H.; Lu, S.C.; Tsai, S.B.; Dong, W. Applying revised gap analysis model in measuring hotel service quality. SpringerPlus 2016, 5, 1191. [CrossRef] [PubMed]

(C) 2018 by the authors. Licensee MDPI, Basel, Switzerland. This article is an open access article distributed under the terms and conditions of the Creative Commons Attribution (CC BY) license (http:/ / creativecommons.org/licenses/by/4.0/). 